\title{
Evolution of bidirectional sex change and gonochorism in fishes of the gobiid genera Trimma, Priolepis, and Trimmatom
}

\author{
Tomoki Sunobe $^{1} \cdot$ Tetsuya Sado $^{2} \cdot$ Kiyoshi Hagiwara $^{3}$ - Hisaya Manabe ${ }^{4}$. \\ Toshiyuki Suzuki $^{5}$ - Yasuhisa Kobayashi ${ }^{6} \cdot$ Makoto Sakurai $^{7}$ - Shin-ichi Dewa ${ }^{8}$. \\ Midori Matsuoka $^{9} \cdot$ Akihiko Shinomiya $^{9} \cdot$ Kazuya Fukuda $^{1} \cdot$ Masaki Miya $^{2}$
}

Received: 16 July 2016 / Revised: 17 January 2017 / Accepted: 20 January 2017 / Published online: 1 March 2017

(C) The Author(s) 2017. This article is published with open access at Springerlink.com

\begin{abstract}
Size-advantage and low-density models have been used to explain how mating systems favor hermaphroditism or gonochorism. However, these models do not indicate historical transitions in sexuality. Here, we investigate the evolution of bidirectional sex change and gonochorism by phylogenetic analysis using the mitochondrial gene of the gobiids Trimma (31 species), Priolepis (eight species), and Trimmatom (two species). Trimma and Priolepis formed a clade within the sister group Trimmatom. Gonadal histology and rearing experiments revealed that Trimma marinae, Trimma nasa, and Trimmatom spp. were gonochoric, whereas all other Trimma and Priolepis spp. were bidirectional sex changers or inferred ones. A maximum-likelihood reconstruction analysis demonstrated that the common ancestor of the three genera was gonochoristic. Bidirectional sex change probably evolved
\end{abstract}

Communicated by: Sven Thatje

Electronic supplementary material The online version of this article (doi:10.1007/s00114-017-1434-z) contains supplementary material, which is available to authorized users.

Tomoki Sunobe

sunobe@biscuit.ocn.ne.jp

1 Laboratory of Fish Behavioral Ecology, Tateyama Station, Field Science Center, Tokyo University of Marine Science and Technology, 670 Banda, Tateyama 294-0308, Japan

2 Department of Zoology, Natural History Museum and Institute, 955-2 Aoba-cho, Chuo-ku, Chiba 260-8682, Japan

3 Yokosuka City Museum, 95 Fukada-dai, Yokosuka 238-0016, Japan

4 Education Center, Kagoshima University, Korimoto, Kagoshima 890-0065, Japan from gonochorism in a common ancestor of Trimma and Priolepis. As the gonads of bidirectional sex changers simultaneously contain mature ovarian and immature testicular components or vice versa, individuals are always potentially capable of functioning as females or males, respectively. Monogamy under low-density conditions may have been the ecological condition for the evolution of bidirectional sex change in a common ancestor. As T. marinae and T. nasa are a monophyletic group, gonochorism should have evolved from bidirectional sex change in a common ancestor.

Keywords Bidirectional sex change $\cdot$ Phylogenetic analysis · Size-advantage model $\cdot$ Low-density model $\cdot$ Mating system · Gobiidae
5 Kawanishi-Midoridai Senior High School, Koyodai, Kawanishi, Hyogo 666-0115, Japan

6 Department of Fisheries, Faculty of Agriculture, Kindai University, Nara 631-8505, Japan

7 Kagoshima Immaculate Heart College, 4-22-1 Toso, Kagoshima 890-8525, Japan

8 Diving Service Umi-Annai, 7-7 Masagohonmachi, Kagoshima 890-0067, Japan

9 Faculty of Fisheries, Kagoshima University, Kagoshima 890-0056, Japan 


\section{Introduction}

The evolution of sequential hermaphroditism in fish has been studied in relation to a central hypothesis called the sizeadvantage (SA) model. This model predicts that protogyny (sex change from female to male) and protandry (sex change from male to female) are favored by polygynous and random mating, respectively (Ghiselin 1969; Warner 1975, 1984). The reproductive success of larger males may be higher than that of smaller males in a polygynous system, resulting from female mate choice for larger males or male-male competition. Protogynous sex change is adaptive under this condition, with fish functioning as females at a smaller size and as males at a larger size. In contrast, male reproductive success is equal among size classes under conditions in which both sexes mate randomly with no mate choice. Protandrous sex change is favored under this condition because female fecundity increases linearly with size, and reproductive success is usually higher in larger females than in males of the same size. Empirical studies (e.g., in Labridae, Platycephalidae, Pomacanthidae, Pomacentridae, and Serranidae) show that these predictions correspond well with the observations (Kuwamura and Nakashima 1998; Munday et al. 2006).

In addition to these types of sex change, information on bidirectional sex change (sex change from female to male and male to female) has been accumulating in Epinephelinae (Serranidae), Cirrhitidae, Gobiidae, Labridae, Pomacanthidae, Pomacentridae, and Pseudochromidae (Munday et al. 2010; Kuwamura et al. 2015). Labroides dimidiatus (Labridae), Centropyge ferrugata (Pomacanthidae), Dascyllus aruanus (Pomacentridae), and Cirrhitichthys falco (Cirrhitidae) are harem polygynous species that change sex from female to male when a dominant male disappears, as in protogynous fishes. However, sex change from male to female takes place in the smaller male of male-male pair under low-density conditions induced by experimental removing a female (Kuwamura et al. 2011, 2014, 2015) or natural disappearance of females (Kadota et al. 2012). In the monogamous coral dwelling gobiid fish Paragobiodon echinocephalus and Gobiodon histrio, bidirectional sex change takes place in male-male and female-female pairs. This system is adaptive if the closest individual is of the same sex after loss of a mate because long-distance movement between host corals may risk increased predation (Kuwamura et al. 1994; Munday 2002).

These studies explain how these types of sex change are adaptive in each social system. However, such observations do not explain the genealogical aspects of hermaphroditism. Sequential and simultaneous hermaphrodites have been reported in 27 teleost families of seven orders (Sadovy de Mitcheson and Liu 2008). Large-scale fish phylogeny studies indicate that hermaphroditism evolved independently in various taxa (Ross 1990; Mank et al. 2006). Fortunately, recent advances in phylogenetic analysis have clarified historical aspects of hermaphroditism in detail (Erisman et al. 2013). Protogynous sex change in the humbug damselfish (Dascyllus) may have evolved once in the ancestor of the genus, and the ability to change sex was lost in the ancestor of one of the clades (MacCafferty et al. 2002). Reconstruction of the phylogeny of the sexual patterns in Serranidae showed that gonochorism and simultaneous hermaphroditism evolved from protogyny as the ancestral condition (Erisman et al. 2009; Erisman and Hastings 2011). A comparative phylogenetic tree analysis in Epinephelinae (Serranidae) and Labridae indicated that the type of mating system, either polygyny or group spawning, is important in the evolution of protogyny or gonochorism, respectively, as predicted by the SA model (Molloy et al. 2007; Erisman et al. 2009; Kanzancioğlu and Alonzo 2010).

Trimma, Priolepis, and Trimmatom are small colorful gobiid fishes, including 92, 34, and seven valid species, respectively, distributed on rocky and coral reefs of temperate and tropical waters in the Indo-Pacific Ocean; Priolepis also has an extended distribution into the Atlantic Ocean (Winterbottom and Emery 1981; Winterbottom 2001; Nogawa and Endo 2007; Hoese and Larson 2010; Suzuki et al. 2012; Winterbottom et al. 2015). Winterbottom et al. (2014) analyzed cryptic Trimma spp. using partial nucleotide sequences from the cytochrome $c$ oxidase I (COI) gene and revealed 94 potential species. These genera are very closely related and comprise a monophyletic group in Gobiidae (Winterbottom and Burridge 1992; Thacker 2009).

Bidirectional sex change has been reported previously in T. grammistes, T. kudoi, T. okinawae, T. yanagitai, P. akihitoi, $P$. cincta, P. latifascima, and P. semidoliata. In most cases, larger individuals of these species change to males and smaller individuals change to females in female-female and malemale pairs, respectively (Sunobe and Nakazono 1993; Shiobara 2000; Manabe et al. 2008, 2013; Sakurai et al. 2009). Harem polygyny is the Trimma okinawae mating system under natural conditions. Sex change from female to male occurs after the male disappears or becomes solitary; a solitary male changes sex to female when it joins another group as a subordinate (Sunobe and Nakazono 1990; Manabe et al. 2007). The $P$. cincta mating system is monogamous (Sunobe and Nakazono 1999), and male-female pairs of P. akihitoi and $P$. semidoliata appear in caves or rocky crevices, suggesting a monogamous system (Manabe et al. 2013). The gonads of these species simultaneously comprise ovarian and testicular portions, which are apparently separated by a thin wall of connective tissue (Sunobe and Nakazono 1993; Shiobara 2000; Manabe et al. 2008, 2013; Sakurai et al. 2009). Our recent study revealed that Trimma marinae is a gonochore with a monogamous mating system (Fukuda et al. 2017). However, no information is available on the sexuality or reproductive ecology of Trimmatom. 
In this study, we analyzed the phylogenetic relationships of Trimma (31 species), Priolepis (eight species), and Trimmatom (two species), based on the nucleotide sequences from the mitochondrial ND4/5 gene region. We also present the sexuality of these species based on gonadal histology and rearing experiments. Lastly, we discuss the historical transitions of sexuality and the mating systems of species in these three genera.

\section{Materials and methods}

\section{Taxon sampling}

To reconstruct the evolution of bidirectional sex change and gonochorism in the three closely related gobiid genera, we sampled 31, eight, and two species of Trimma, Priolepis, and Trimmatom, respectively. We also sampled additional seven species as gobioid outgroups, and final rooting of the tree was made with a member of one of the most basally diverged families (Rhyacichthyidae: Rhyacichthys aspro) (Thacker 2009; Aggorreta et al. 2013) (Supplementary Table 1).

\section{DNA methods}

The mitochondrial ND4/ND5 gene region outperforms commonly used mtDNA genes, such as COI, cyt $b$, and $12 \mathrm{~S} / 16 \mathrm{~S}$ rRNA genes in phylogenetic analyses at broad taxonomic scales because it is relatively long (ca. $3.4 \mathrm{~kb}$ ) and contains more phylogenetically informative variation at the first and second codon positions (Miya and Nishida 2000; Miya et al. 2006). Accordingly, we designed new polymerase chain reaction (PCR) primers to effectively amplify the gobioid ND4/ ND5 region with reference to available whole gobioid mitogenomic sequences (Miya et al. 2003, 2013; Supplementary Fig. 1). We generated new ND4/5 gene region sequences from the 48 species using a combination of long and short PCR and direct sequencing techniques following the protocol suggested by Miya et al. (2006) (Supplementary Table 2).

\section{Phylogenetic analysis}

Nucleotide sequences from the 48 species were concatenated and subjected together to multiple alignment using MAFFT ver. 6 (Katoh and Toh 2008). Unambiguously aligned sequences (total, $3679 \mathrm{bp}$ ) were used to construct a dataset that excluded quickly saturated transitional changes in the third codon position by converting purine $(\mathrm{A} / \mathrm{G})$ and pyrimidine $(\mathrm{C} / \mathrm{T})$ nucleotides to A and $\mathrm{C}$, respectively, following Saitoh et al. (2006). Only transversions are considered by retaining all available positions in the dataset, so "noise" is effectively removed and the apparent loss of signals is avoided. The dataset was divided into four partitions (three partitions for the protein-coding genes and one partition for the tRNA genes) and subjected to partitioned maximum-likelihood (ML) analysis using RAxML ver. 7.2.8 (Stamatakis 2006). A general time-reversible model with sites following a discrete gamma distribution $(\mathrm{GTR}+\Gamma)$ was used, and a rapid bootstrap analysis was conducted with 1000 replications ( $-\mathrm{f} \mathrm{a}$ option).

\section{Tracing character evolution}

The evolution of bidirectional sex change and gonochorism was reconstructed based on the best-scoring ML tree under the ML optimality criterion using Mesquite ver. 2.6 (Maddison and Maddison 2010). Two character states of sexuality were assigned: gonochorism (character state 0 ) and confirmed or likely bidirectional sex change (state 1).

\section{Determining sexuality}

Rearing experiments were conducted with $T$. caesiura, T. maiandros, T. naudei, and Trimmatom sp. to confirm sex change. Five, three, and three T. caesiura, T. naudei, and T. maiandros individuals, respectively, were collected on April 14 and 15, 2014, at Atetsu, Amami Island, Japan, and 12 Trimmatom sp. were collected on May 8 and 9, 2009, at Tsuchihama, Amami Island, Japan. The fish were brought to the laboratory, anesthetized in $100 \mathrm{ppm}$ quinaldine, measured in total length (TL) to the nearest $0.1 \mathrm{~mm}$, and identified by body size. Sex was determined from the shape of urogenital papilla: bulbous with several processes at the opening in females or tapered posteriorly in males, as determined in other gobiid species (Sunobe and Nakazono 1993; Kuwamura et al. 1994; Shiobara 2000; Manabe et al. 2008, 2013; Sakurai et al. 2009) (Fig. 1 shows urogenital papillae of T. kudoi, which is conspecific with Trimma sp. in Manabe et al. [2008]).
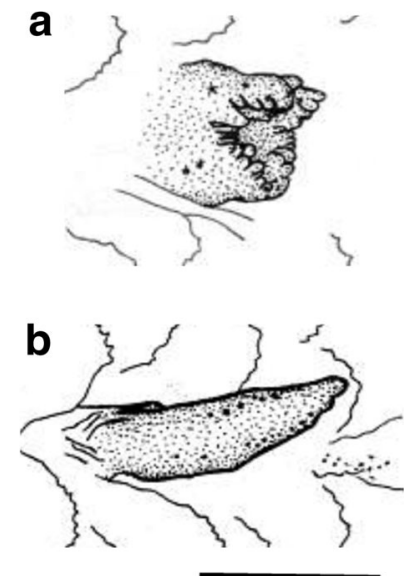

Fig. 1 Urogenital papillae of female (a) and male (b) in Trimma kudoi. Scale $1 \mathrm{~mm}$ 
Table 1 Results of the Trimma caesiura, Trimma maiandros, and Trimma naudei rearing experiments

Individual name Date of spawning Sex role Date of removal Date of spawning Sex role Date of return Date of spawning Sex role TL at end (mm TL)

\begin{tabular}{|c|c|c|c|c|c|c|c|c|c|}
\hline \multicolumn{10}{|c|}{ Trimma caesiura } \\
\hline TC1 (31.0) & & Male & May 18 & & & June 7 & & Male & 35.0 \\
\hline TC2 (26.5) & May 9 & Female & & & Male & & June 28 & Female & 33.5 \\
\hline TC3 (23.0) & May 14 & Female & & May 24 & Female & & June 10 & Female & 27.6 \\
\hline \multicolumn{10}{|c|}{ Trimma maiandros } \\
\hline TM1 (27.0) & & Male & May 16 & & & May 23 & & Male & 29.0 \\
\hline TM2 (26.0) & May 16 & Female & & & Male & & May 31 & Female & 27.5 \\
\hline TM3 (23.0) & April 29 & Female & & May 19 & Female & & May 23 & Female & 25.5 \\
\hline \multicolumn{10}{|l|}{ Trimma naudei } \\
\hline TN1 (34.0) & & Male & May 13 & & & June 7 & June 26 & Female & 35.5 \\
\hline TN2 (33.5) & May 7 & Female & & & Male & & & Male & 37.0 \\
\hline TN3 (32.0) & May 2 & Female & & May 16 & Female & & June 8 & Female & 34.0 \\
\hline TN4 (28.0) & May 1 & Female & & May 20 & Female & & June 8 & Female & 31.0 \\
\hline
\end{tabular}

T. caesiura, T. maiandros, and T. naudei specimens were held together in their respective aquaria $(60 \times 35 \times 30 \mathrm{~cm})$ (Table 1). The sexual functions of the individuals were determined by spawning behavior, and the males were removed and placed in another aquarium $(60 \times 35 \times 30 \mathrm{~cm})$. If sex change to male was confirmed among the remaining females, the male previously removed was returned to its former aquarium. Subsequent observations revealed whether male-tofemale sex change had occurred.

Six male and six female Trimmatom sp. were kept in male-female pairs in six aquaria $(30 \times 20 \times 23 \mathrm{~cm})$ (Table 2). They were reared until spawning to confirm sexual function. The fish were then exchanged among the pairs to establish male-male and female-female pairs for 1 month. We observed whether spawning occurred or not by sex change. If spawning was not observed, sex was determined by the structure of the urogenital papilla and gonadal histology.

Water in all aquaria was circulated continuously through gravel filters and maintained at $24-28^{\circ} \mathrm{C}$. Fish were fed formula food and Artemia salina larvae. A half-cut vinyl chloride pipe ( $5 \mathrm{~cm}$ inner diameter and $5 \mathrm{~cm}$ length) was added to each aquarium as a spawning nest.

We examined the gonads of the species listed, except those of T. grammistes, T. kudoi, T. okinawae, T. yanagitai, and eight Priolepis spp., whose gonadal structures have been published (Sunobe and Nakazono 1993; Shiobara 2000; Manabe et al. 2008, 2013; Sakurai et al. 2009; Cole 2010; Supplementary Table 1). Specimens of T. caudomaculatum, T. flavatram, T. hayashii,

Table 2 Results of the Trimmatom sp. rearing experiments

\begin{tabular}{|c|c|c|c|c|c|c|c|}
\hline $\begin{array}{l}\text { Individual name } \\
\text { (mm TL) }\end{array}$ & $\begin{array}{l}\text { Shape of urogenital } \\
\text { papilla at start }\end{array}$ & $\begin{array}{l}\text { Date of } \\
\text { spawning }\end{array}$ & Sex role & Exchange & Individual name & $\begin{array}{l}\text { Shape of urogenital } \\
\text { papilla at end }\end{array}$ & $\begin{array}{l}\text { Gonad } \\
\text { histology }\end{array}$ \\
\hline Tom1 (23.0) & Tapered & June 30 & Male & Pairing with the same sex & Tom1 & Tapered & Testis \\
\hline Tom2 (22.0) & Bulbous & & Female & & Tom3 & Tapered & Testis \\
\hline Tom3 (23.0) & Tapered & July 30 & Male & & Tom2 & Bulbous & Ovary \\
\hline Tom4 (20.5) & Bulbous & & Female & & Tom4 & Bulbous & Ovary \\
\hline Tom5 (28.0) & Tapered & May 30 & Male & Pairing with the same sex & Tom5 & Tapered & Testis \\
\hline Tom6 (28.0) & Bulbous & & Female & & Tom7 & Tapered & Testis \\
\hline Tom7 (25.0) & Tapered & June 2 & Male & & Tom6 & Bulbous & Ovary \\
\hline Tom8 (24.0) & Bulbous & & Female & & Tom8 & Bulbous & Ovary \\
\hline Tom9 (24.0) & Tapered & July 21 & Male & Pairing with the same sex & Tom9 & Tapered & Testis \\
\hline Tom10 (24.0) & Bulbous & & Female & & Tom11 & Tapered & Testis \\
\hline Tom11 (22.0) & Tapered & July 25 & Male & & Tom10 & Bulbous & Ovary \\
\hline Tom12 (23.0) & Bulbous & & Female & & Tom12 & Bulbous & Ovary \\
\hline
\end{tabular}


Fig. 2 Phylogenetic tree for the maximum likelihood analysis and reconstruction of the evolution of bidirectional sex change and gonochorism. Numbers next to the branches indicate bootstrap probabilities $\geq 40 \%$ based on 1000 replications

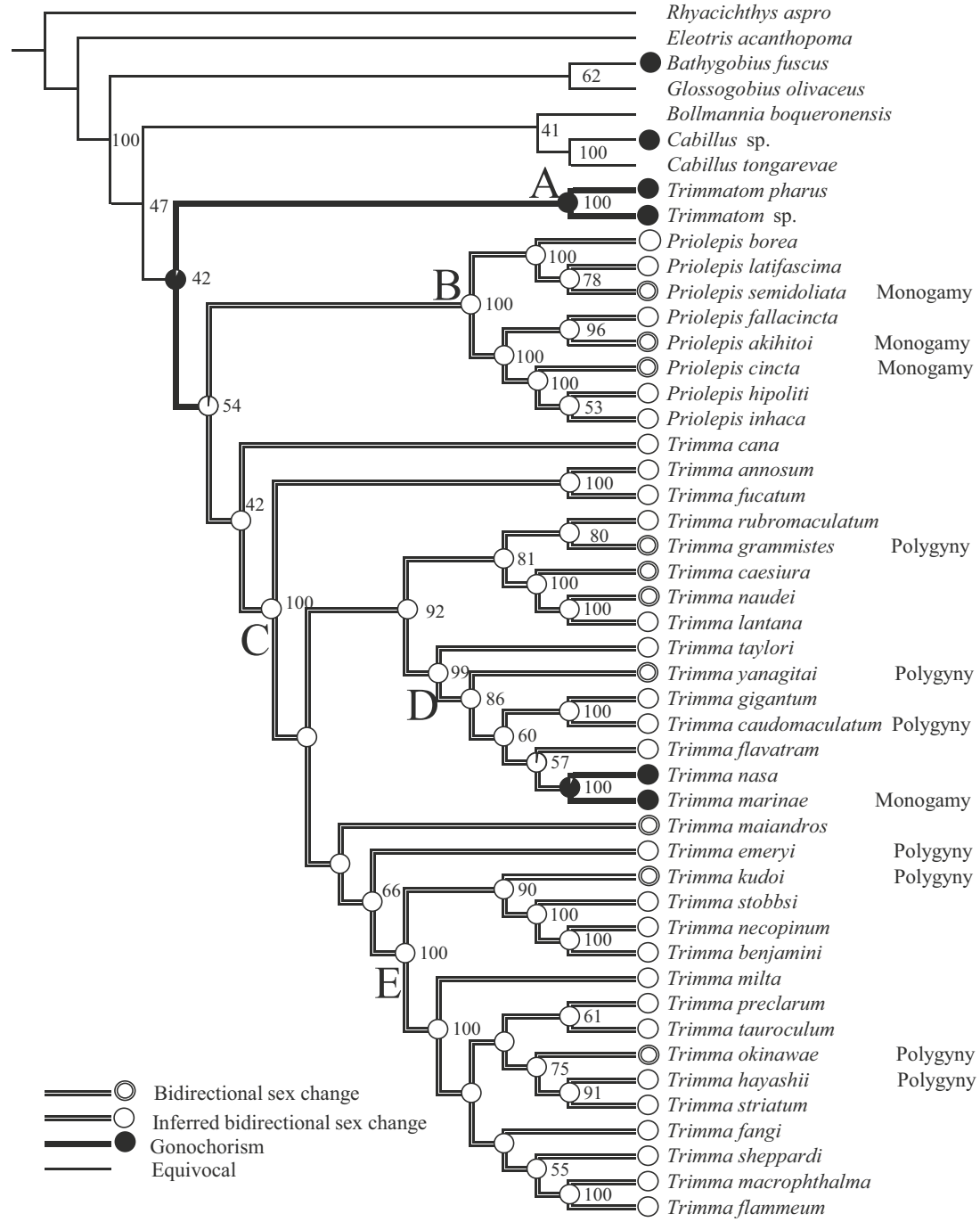

T. maiandros, T. marinae, T. milta, T. taylori, Trimmatom sp., Trimmatom pharus, Cabillus sp., and Bathygobius fuscus were collected by hand net using scuba or by snorkeling, and Trimma rubromaculatum was obtained from an ornamental fish shop. The fish were brought to the laboratory, anesthetized in 100 ppm MS-222, measured in TL to the nearest $0.5 \mathrm{~mm}$, and sexed by the above methods. These specimens were fixed in Bouin's solution for $24 \mathrm{~h}$ and preserved in $70 \%$ ethanol. The abdomens were embedded in paraffin, and whole gonads were sectioned serially at $5 \mu \mathrm{m}$ and stained with hematoxylin and eosin. We examined the gonads of 19 Trimma spp. and T. pharus specimens deposited in the Royal Ontario Museum, the Yokosuka City Museum, and Kanagawa Prefectural Museum of Natural History (Supplementary Table 1). We dissected and extracted the abdominal organs containing the gonads after determining sex by the urogenital papilla structure and prepared the tissues following the method outlined above.

\section{Results}

\section{Phylogenetic relationships}

Trimma, Priolepis, and Trimmatom were recovered together as a monophyletic group in the ML tree by only $42 \%$ bootstrap probability (BP), and Trimma and Priolepis formed a clade within the sister group Trimmatom with a 54\% BP value. However, monophyly of each genus was strongly supported by a $100 \%$ BP value (clades A, B, and C) when the most basally diverged Trimma cana was excluded from the genus (Fig. 2).

\section{Rearing experiments and gonad histology}

The T. caesiura, T. maiandros, and T. naudei rearing experiments showed that larger and smaller individuals functioned as males and females, respectively. After removing the males (TC1, TM1, and TN1), the largest females (TC2, TM2, and 
Fig. 3 Gonadal structures of females $(\mathbf{a}, \mathbf{c}, \mathbf{e})$ and males $(\mathbf{b}, \mathbf{d}$, f) in Trimma caesiura $(\mathbf{a}, \mathbf{b})$, Trimma hayashii (c, d), and Trimma sheppardi $(\mathbf{e}, \mathbf{f}) . O$ ovary, $T$ testis, $A G S$ accessory gonadal structure. Scale $0.5 \mathrm{~mm}$

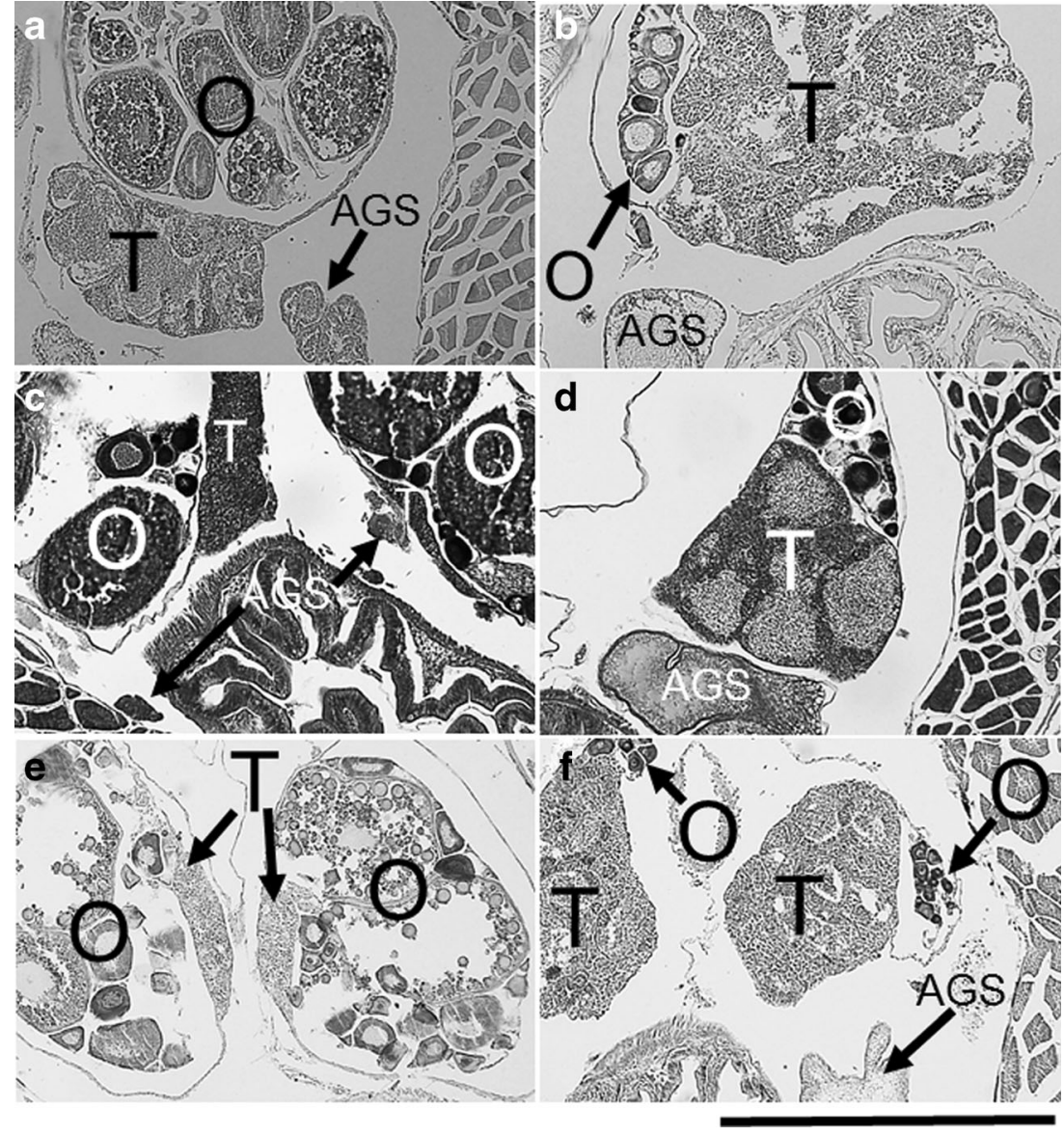

TN2) changed sex to males. When the males were returned, TC2, TM2, and TN1 changed back to females. These observations indicate that these species change sex bidirectionally and that their sex role is determined by body size; larger fish are males and smaller fish are females (Table 1). The gonadal structures in these species simultaneously consisted of both ovarian and testicular portions separated by a thin wall of connective tissue and an accessory gonadal structure (AGS; Cole 1990, 2010) (Fig. 3a, b shows T. caesiura gonads as an example). In female, the ovary contained oocytes in various stages of development. The testis and AGS were undeveloped (Fig. 3a). In male, the testis was filled with spermatozoa. The AGS was developed, and ovarian tissue was filled with young oocytes (Fig. 3b). The same gonadal structure as that described for the above species was also found in the other Trimma spp., except T. marinae and T. nasa (Fig. 3c-f shows T. hayashii and T. sheppardi gonads as examples).

No spawning was observed in any pair during the Trimmatom $\mathrm{sp}$. exchange experiments. At the end, shape of urogenital papillae of the individuals did not change, and there was no signal for sex change by gonad histology (Table 2). We did not detect intersexual gonads in T. marinae, T. nasa, Trimmatom $\mathrm{sp}$., and $T$. pharus. The male gonads consisted of testes with the AGS, and the female gonads are composed of only ovaries (Fig. 4). The gonadal structures of outgroup species Cabillus sp. and B. fuscus were the same as those of these four species.

\section{Discussion}

\section{Phylogenetic relationships}

Thacker (2009) analyzed the phylogeny of Gobioidei using the ND1/2 and COI regions and reported that Trimma caesiura, Priolepis cincta, Priolepis eugenius, and Trimmatom eviotops form a monophyletic group with strong support. These results suggest a close relationship among these three genera. Winterbottom et al. (2014) presented the relationships among cryptic Trimma species using partial COI gene nucleotide sequences. Species in clade D, except T. gigantum and T. caudomaculatum, and those in clade E (Fig. 2), which were supported by a high BP value, corresponded with the grouping reported by Winterbottom et al. (2014), although the detailed topologies within the group differed. The concordance of these results using different methods suggests that the relationships among these species have been correctly deduced. 
Fig. 4 Gonadal structures of females $(\mathbf{a}, \mathbf{c}, \mathbf{e}, \mathbf{g})$ and males $(\mathbf{b}$, $\mathbf{d}, \mathbf{f}, \mathbf{h})$ in Trimma marinae $(\mathbf{a}, \mathbf{b})$ Trimma nasa $(\mathbf{c}, \mathbf{d})$, Trimmatom sp. (e, f) and Trimmatom pharus $(\mathbf{g}, \mathbf{h}) . O$ ovary, $T$ testis, $A G S$ accessory gonadal structure. Scale $0.5 \mathrm{~mm}(\mathbf{a}, \mathbf{b}, \mathbf{c}, \mathbf{d}, \mathbf{e}, \mathbf{g})$ and $0.2 \mathrm{~mm}(\mathbf{f}, \mathbf{h})$

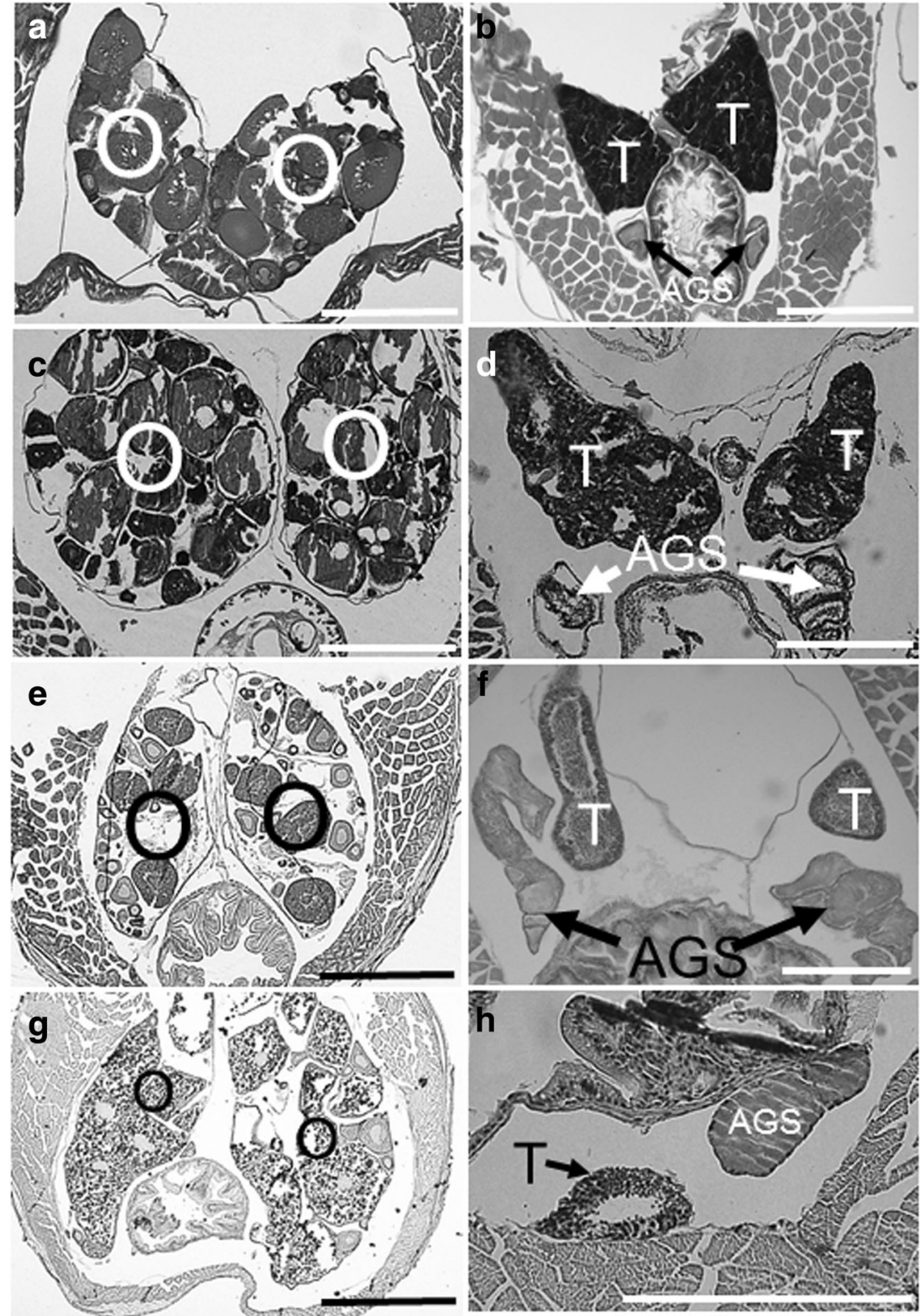

As mentioned above, there are 92, 34, and seven valid species in Trimma, Priolepis, and Trimmatom, respectively, but in this study, we examined only 31 , eight, and two species, respectively. In addition, we did not investigate the related genera Egglestonichthys and Paratrimma (Winterbottom and Burridge 1992) due to difficulty to obtain specimens. Future studies will examine their phylogenetic relationships by analyzing a greater number of species and genera, using other genes as well as mitochondrial gene ND4/5.

\section{Determination of sexuality}

The results show that T. caesiura, T. maiandros, and T. naudei exhibited bidirectional sex change, and the gonadal structures simultaneously consisted of both ovarian and testicular portions. The same gonadal structures are also reported in T. grammistes, T. kudoi, T. okinawae, T. yanagitai, P. akihitoi, P. cincta, P. latifascima, and P. semidoliata in which bidirectional sex change has been confirmed previously (Sunobe and Nakazono 1993; Shiobara 2000; Manabe et al. 2008, 2013; Sakurai et al. 2009).

This type of gonadal structure is also found in the male phase of protandrous species, Amphiprion akallopisos (Pomacentridae), Acanthopagrus schlegelii (Sparidae), and Thysanophrys celebica (Platycephalidae). The testicular part is active, while the ovarian part is inactive. However, the testicular part disappears after sex change from male to female, and the active ovarian part remains (Fricke and Fricke 1977; Chang and Yueh 1990; Sunobe et al. 2016). 
A similar gonadal structure is reported in the simultaneous hermaphrodites Serranus scriba (Serranidae) and Kryptolebias marmoratus (Rivulidae). Gonads of these species are composed of simultaneously active ovarian and testicular part. In these species, one individual can function as male and female at the same time (Tuset et al. 2005; Sakakura et al. 2006).

Although both ovary and testis are present at the same time in one individual in these Trimma and Priolepis spp., either the ovary or the testis is active or inactive in male and female phases, respectively (Fig. 3), unlike the above protogynous and simultaneous hermaphrodite species. As the ovarian part remains after sex change from female to male, the male can revert to female.

The same gonadal structure is also found in the other Trimma spp., except T. marinae and T. nasa in this study, and in P. borea, P. fallacincta, P. hipoliti, and P. inhaca (Cole 2010; Manabe et al. 2013). Although we did not confirm bidirectional sex change in field observations or rearing experiments on these species, they are inferred to exhibit bidirectional sex change.

Cole (2010) shows that a precursor AGS (pAGS) is detectable in the ovary of protogynous gobiid fish (Bryaninops, Elacatinus, Fusigobius, and Lophogobius) as a valid indicator of protogyny. In T. marinae, T. nasa, and Trimmatom sp., intersexual gonads were not detected, and the female gonads are composed of only ovaries without a pAGS (Fig. 4a-f). T. marinae did not change sex in male-only or female-only groups after a 2-month rearing experiment (Fukuda et al. 2017). Female T. nasa are larger than males because growth rate of the former is faster than that of the latter (Winterbottom and Southcott 2008), not showing protandrous sex change. At the end of Trimmatom sp. exchange experiments, any individual did not spawn, and there was no evidence suggesting sex change from either changes in the papillae or gonad histology (Table 2). These data strongly suggest that three species are gonochores. Although we did not conduct $T$. pharus rearing experiments, we regard this species as a gonochore because the gonadal structures of all specimens examined were the same as those of the above species (Fig. 4g, h). For sexuality of the outgroup species, Cabillus sp. and B. fuscus should be identified as a gonochore by lack of pAGS in female gonads.

The conclusion for determination of sexuality on the above species is listed in Fig. 2.

\section{Evolution of bidirectional sex change and gonochorism and the ancestral mating system}

Here, we show the nodes at which bidirectional sex change or gonochorism evolved, although the proposed phylogenetic hypothesis potentially could be improved, as mentioned above.
As a common ancestor of Trimma, Priolepis, and Trimmatom was predicted as a gonochore, the evolution of bidirectional sex change from gonochorism should occur in a Trimma and Priolepis common ancestor (Fig. 2). Although there is no information on sexuality of outgroup species other than Cabillus sp. and B. fuscus, these data suggest that the common ancestors of Trimma, Priolepis, Trimmatom and these outgroup species are gonochores. The theoretical and empirical studies indicate that mating system is one of the main selection pressures favoring sex change (Ghiselin 1969; Warner 1975, 1984; Kuwamura and Nakashima 1998; Munday et al. 2006, 2010; Sadovy de Mitcheson and Liu 2008). We address the ecological condition for evolution of bidirectional sex change in the following cases to discuss which type of mating system was adopted by the common ancestor.

In polygynous species exhibiting bidirectional sex change, such as L. dimidiatus, D. aruanus, C. ferrugata, and C. falco, females change to males after the dominant male disappears or if a branching harem forms (Kuwamura 1981; Coates 1982; Sakai 1997; Kadota et al. 2012). Female mate choice for larger males or male-male competition, which favors protogyny as predicted by the SA model, should occur in populations which individuals frequently interact. In this condition, a male can monopolize several females, and males compete with resources or females. Male-to-female sex change occurs by establishing a pair between the nearest or second-nearest males after experimental removal or natural disappearance of females. The reverse sex change condition seems to correspond with low density (Kuwamura et al. 2011, 2014, 2015; Kadota et al. 2012). As territorial males rarely lose their mates, such a low-density condition could occur near the edge of the distribution (Kuwamura et al. 2011). These results suggest that female-to-male sex change evolved first in the center of the distribution and that male-to-female sex change was favored later.

Monogamous gobiid fish, such as $P$. echinocephalus and G. histrio, are obligate coral-dwelling species. These species exhibit female-to-male and male-to-female sex change by mating with individuals of the same sex. If the mate is lost or the coral dies, it is more advantageous for both sexes to re-establish the pair with a nearby consensual individual than to search for a heterosexual fish over a long distance because it may increase predation risk (Kuwamura et al. 1994; Nakashima et al. 1995; Munday 2002). Ghiselin (1969) proposed a "low-density model" in which simultaneous hermaphroditism is adaptive in a species with low mobility or low population density to reduce mating opportunities. The above cases are very consistent with this model. As any individual could function as a male or a female, the evolution of female-to-male and male-to-female (bidirectional) sex change may have occurred simultaneously. 
T. okinawae, T. grammistes, T. kudoi, T. yanagitai, T. caudomaculatum, T. hayashii, and T. emeryi inhabit groups of more than three individuals, and the mating system is polygynous (Sunobe and Nakazono 1990; Shiobara 2000; Manabe et al. 2007, 2008; Sakurai et al. 2009; Sunobe unpublished data; see also Fig. 2). Meanwhile, $P$. akihitoi, $P$. cincta, and $P$. semidoliata appear as a pair or singly and are monogamous under a low-density condition (Sunobe and Nakazono 1999; Manabe et al. 2013; see also Fig. 2).

Although data on the mating system for both genera are limited, that of the common ancestor would have been either polygyny or monogamy. Figure 2 indicates that bidirectional sex change evolved from gonochorism without protogyny. The structure of intersexual gonads (Fig. 3) indicates that an individual could function as a male or a female under any condition. Therefore, the ecological conditions for evolution of bidirectional sex change in the common ancestor may correspond to the latter case above, that is, monogamy under lowdensity conditions.

T. okinawae is harem polygynous and is the only species in which bidirectional sex change was confirmed under natural conditions among Trimma spp. Female-to-male sex change occurs when the dominant male disappears or the female loses its mate. Male-to-female sex change is observed in bachelor males after mating with larger males (Manabe et al. 2007). The conditions for sex change are primarily the same as those in other polygynous species, as mentioned above. However, Fig. 2 shows that bidirectional sex change was not independently favored in T. okinawae compared to other related species. Polygyny may have evolved during speciation from the common ancestor to Trimma, but the trait for male-to-female sex change was not lost. It may be adaptive for T. okinawae to retain the ability to change sex bidirectionally because the study described above indicates that a low-density condition occurs occasionally.

Figure 2 shows that gonochorism should have evolved from bidirectional sex change in the common ancestor of the gonochoristic species T. marinae and T. nasa. Evolution from hermaphroditism to gonochorism has been reported in Dascyllus (Pomacentridae), Labridae, Serranidae, and Sparidae (McCafferty et al. 2002; Erisman et al. 2009, 2013; Erisman and Hastings 2011). A pairing T. marinae female occupies a male and excludes other females, resulting in monogamy, because the ability to care paternally may be limited to one clutch. There are two explanations for the adaptive significance of gonochorism in this species. First, as this species forms aggregations, both sexes can easily mate with a new mate without changing sex. Second, it may be costly to change sex due to a short lifespan because an individual cannot spawn during the sex change period (Fukuda et al. 2017). Data on the reproductive ecology of the species in clade D (Fig. 2) are needed to clarify the evolution of gonochorism in the common ancestor of T. marinae and T. nasa. However, data on T. taylori, T. gigantum, T. flavatram, and T. nasa are unavailable. Thus, further study is needed to clarify the reproductive ecology of these species.

Acknowledgments We are grateful to Richard Winterbottom and Don Stacey (Royal Ontario Museum) for loaning specimens and providing permission to dissect them. Thanks are also due to Tatsuzo Yamada, Yoshihiro Yoshiura, Hiroyuki Kanehara, Kaori Nakatsuka, Sadao Yokoyama, Hiroshi Senou, and Jiro Sakaue for their cooperation throughout the study. We are indebted to anonymous reviewers for their valuable comments on the manuscript. This study was supported by JSPS KAKENHI Grants to T. Sunobe (nos. 19570016, 24370006, and 16K07507) from the Japan Society for the Promotion of Science.

Compliance with ethical standards The experimental protocol in studies was approved by Tokyo University of Marine Science and Technology where the studies were conducted, and all used procedures were carried out in accordance with approved guidelines.

Competing interests The authors declare that they have no competing interests.

Open Access This article is distributed under the terms of the Creative Commons Attribution 4.0 International License (http:// creativecommons.org/licenses/by/4.0/), which permits unrestricted use, distribution, and reproduction in any medium, provided you give appropriate credit to the original author(s) and the source, provide a link to the Creative Commons license, and indicate if changes were made.

\section{References}

Agorreta A, San Mauro D, Schliewen U, Van Tassell JL, Kovačić M, Zardoya RL, Rüber L (2013) Molecular phylogenetics of Gobioidei and phylogenetic placement of European gobies. Mol Phylogenet Evol 69:619-633

Chang C, Yueh W (1990) Annual cycle of gonadal histology and steroid profiles in the juvenile males and adult females of the protandrous black porgy, Acanthopagrus schlegeli. Aquaculture 91:179-196

Coates D (1982) Some observations on the sexuality of humbug damselfish, Dascyllus aruanus (Pisces, Pomacentridae) in the field. Z Tierpsychol 59:7-18

Cole KS (1990) Patterns of gonad structure in hermaphroditic gobies (Teleostei: Gobiidae). Environ Biol Fish 28:125-142

Cole KS (2010) Gonad morphology in hermaphroditic gobies. In: Cole KS (ed) Reproduction and sexuality in marine fishes: patterns and processes. University of California Press, Berkley and Los Angeles, California, pp 117-162

Erisman BE, Craig MT, Hastings PS (2009) A phylogenetic test of the size-advantage model: evolutionary changes in mating behavior influence the loss of sex change in a fish lineage. Amer Nat 174:E83E99

Erisman BE, Hastings PA (2011) Evolutionary transitions in the sexual patterns of fishes: insights from a phylogenetic analysis of the seabasses (Teleostei: Serranidae). Copeia 2011:357-364

Erisman BE, Petersen CW, Hastings PA, Warner RR (2013) Phylogenetic perspectives on the evolution of functional hermaphroditism in teleost fishes. Integ Comp Biol 53:736-754

Fricke H, Fricke S (1977) Monogamy and sex change by aggressive dominance in coral reef fish. Nature 266:830-832

Fukuda K, Manabe H, Sakurai M, Dewa S, Shinomiya A, Sunobe T (2017) Monogamous mating system and sexuality in the gobiid fish, Trimma marinae (Actinopterygii: Gobiidae). J Ethol 35:121-130 
Ghiselin MT (1969) The evolution of hermaphroditism among animals. Quart Rev Biol 44:189-208

Hoese DF, Larson HK (2010) Description of two new species of the genus Priolepis from the Indo-Pacific with redescription of Priolepis profunda and Priolepis psygmophilia. Ichthyol Res 57: 373-388

Kadota T, Osato J, Nagata K, Sakai Y (2012) Reversed sex change in the haremic protogynous hawkfish Cirrhitichthys falco in natural conditions. Ethology 118:226-234

Kanzancioğlu E, Alonzo SH (2010) A comparative analysis of sex change in Labridae supports the size advantage hypothesis. Evolution 64:2254-2264

Katoh K, Toh H (2008) Recent developments in the MAFFT multiple sequence alignment program. Brief Bioinform 9:286-298

Kuwamura T (1981) Social structure of the protogynous fish Labloides dimidiatus. Publ Seto Mar Biol Lab 23:117-177

Kuwamura T, Kadota T, Suzuki S (2014) Testing the low-density hypothesis for reversed sex change in polygynous fish: experiments in Labroides dimidiatus. Sci Rep 4:4369

Kuwamura T, Nakashima Y (1998) New aspects of sex change among reef fishes: recent studies in Japan. Environ Biol Fish 52:125-113

Kuwamura T, Nakashima Y, Yogo Y (1994) Sex change in either direction by growth-rate advantage in the monogamous coral goby, Paragobiodon echinocephalus. Behav Ecol 5:434-438

Kuwamura T, Suzuki S, Kadota T (2011) Reversed sex change by widowed males in polygynous and protogynous fishes: female removal experiments in the field. Naturwissenschaften 98:1041-1048

Kuwamura T, Suzuki S, Kadota T (2015) Male-to-female sex change in widowed males of the protogynous damselfish Dascyllus aruanus. J Ethol 34:85-88

Maddison WP, Maddison DR (2010) Mesquite: a modular system for evolutionary analysis Ver. 2.73

Manabe H, Ishimura M, Shinomiya A, Sunobe T (2007) Field evidence for bi-directional sex change in the polygynous gobiid fish Trimma okinawae. J Fish Biol 70:600-609

Manabe H, Matsuoka M, Goto K, Dewa S, Shinomiya S, Sakurai M, Sunobe T (2008) Bi-directional sex change in the gobiid fish Trimma sp.: does size-advantage exist? Behaviour 145:99-113

Manabe H, Toyoda K, Nagamoto K, Dewa S, Sakurai M, Hagiwara K, Shinomiya A, Sunobe T (2013) Bi-directional sex change in seven species of Priolepis (Actinopterygii: Gobiidae). Bull Mar Sci 89: 635-642

Mank JE, Promislow DEL, Avise JC (2006) Evolution of alternative sexdetermining mechanisms in teleost fishes. Biol J Lin Soc 87:83-93

McCafferty S, Bermingham E, Quenouille B, Planes S, Hoelzer G, Asoh K (2002) Historical biogeography and molecular systematics of the Indo-Pacific genus Dascyllus (Teleostei: Pomacentridae). Mol Ecol 11:1377-1392

Miya M, Friedman M, Satoh TP, Takeshima H, Sado T, Iwasaki W, Yamanoue Y, Nakatani M, Mabuchi K, Inoue JG, Poulsen JY, Fukunaga T, Sato Y, Nishida M (2013) Evolutionary origin of the Scombridae (tunas and mackerels): members of a Paleogene adaptive radiation with 14 other pelagic fish families. PLoS One 8: e73535

Miya M, Nishida M (2000) Use of mitogenomic information in teleostean molecular phylogenetics: a tree-based exploration under the maximum-parsimony optimality criterion. Mol Phylogenet Evol $17: 437-455$

Miya M, Saitoh K, Wood R, Nishida M, Mayden RL (2006) New primers for amplifying and sequencing the mitochondrial ND4/ND5 gene region of the Cypriniformes (Actinopterygii: Ostariophysi). Ichthyol Res 53:75-81

Miya M, Takeshima H, Endo H, Ishiguro NB, Inoue JG, Mukai T, Satoh TP, Yamaguchi M, Kawaguchi A, Mabuchi K, Shirai SM, Nishida M (2003) Major patterns of higher teleostean phylogenies: a new perspective based on 100 complete mitochondrial DNA sequences. Mol Phylogenet Evol 26:121-138

Molloy PP, Goodwin NB, Côte IM, Reynolds JD, Gage MJG (2007) Sperm competition and sex change: a comparative analysis across fishes. Evolution 61:640-652

Munday PL (2002) Bi-directional sex change: testing the growth-rate advantage model. Behav Ecol Sociobiol 52:247-254

Munday PL, Buston PM, Warner RR (2006) Diversity and flexibility of sex-change strategies in animals. Trend Ecol Evol 21:89-95

Munday PL, Kuwamura T, Kroon FJ (2010) Bidirectional sex change in marine fishes. In: Cole KS (ed) Reproduction and sexuality in marine fishes: patterns and processes. University of California Press, Berkley and Los Angeles, California, pp 241-271

Nakashima Y, Kuwamura T, Yogo Y (1995) Why be a both-ways sex changer? Ethology 101:301-307

Nogawa Y, Endo H (2007) A new species of the genus Priolepis (Perciformes: Gobiidae) from Tosa Bay, Japan. Bull Natl Mus Nat Sci, Ser A, Suppl 1:153-161

Ross RM (1990) The evolution of sex-change mechanisms in fishes. Environ Biol Fish 29:81-93

Sadovy de Mitcheson Y, Liu M (2008) Functional hermaphroditism in teleosts. Fish Fish 9:1-43

Saitoh K, Sado T, Mayden RL, Hanzawa N, Nakamura K, Nishida M, Miya M (2006) Mitogenomic evolution and interrelationships of the Cypriniformes (Actinopterygii: Ostariophysi): the first evidence toward resolution of higher-level relationships of the World's largest freshwater fish clade based on 59 whole mitogenome sequences. J Mol Evol 63:826-841

Sakai Y (1997) Alternative spawning tactic of female angelfish according to two different context of sex change. Behav Ecol 8:372-377

Sakakura Y, Soyano K, Noakes DLG, Hagiwara A (2006) Gonadal morphology in the self-fertilizing mangrove killifish, Kryptolebias marmoratus. Ichthyol Res 53:427-430

Sakurai M, Nakakoji S, Manabe H, Dewa S, Shinomiya A, Sunobe T (2009) Bi-directional sex change and gonad structure in the gobiid fish Trimma yanagitai. Ichthyol Res 56:82-86

Shiobara Y (2000) Reproduction and hermaphroditism of the gobiid fish, Trimma grammistes, from Suruga Bay, central Japan. Sci Rep Mus, Tokai Univ 2:19-30

Stamatakis A (2006) RAxML-VI-HPC: maximum likelihood-based phylogenetic analyses with thousands of taxa and mixed models. Bioinformatics 22:2688-2690

Sunobe T, Nakazono A (1990) Polygynous mating system of Trimma okinawae (Pisces: Gobiidae) at Kagoshima, Japan with a note on sex change. Ethology 84:133-143

Sunobe T, Nakazono A (1993) Sex change in both directions by alteration of social dominance in Trimma okinawae (Pisces: Gobiidae). Ethology 94:339-345

Sunobe T, Nakazono A (1999) Mating system and hermaphroditism in the gobiid fish, Priolepis cincta, at Kagoshima, Japan. Ichthyol Res 46:103-106

Sunobe T, Sakaida S, Kuwamura T (2016) Random mating and protandrous sex change of the platycephalid fish Thysanophrys celebica (Platycephalidae). J Ethol 34:15-21

Suzuki T, Sakaue J, Senou H (2012) Two new species of the gobiid fish genus Trimma (Actinopterygii: Perciformes: Gobiidae) from Japan and Palau. Bull Natl Mus Nat Sci, Ser A, Suppl 6:67-77

Thacker CE (2009) Phylogeny of Gobioidei and placement within Acanthomorpha, with a new classification and investigation of diversification and character evolution. Copeia 2009:93-104

Tuset VM, García-Díaz MM, González JA, Lorente MJ, Lozano IJ (2005) Reproduction and growth of the painted comber Serranus scriba (Serranidae) of the Marine Reserve of Lanzarote Island (Central-Eastern Atlantic). Estuar Coast Shelf Sci 64:335-346

Warner RR (1975) The adaptive significance of sequential hermaphroditism in animals. Amer Nat 109:61-82 
Warner RR (1984) Mating behavior and hermaphroditism in coral reef fishes. Amer Sci 72:128-136

Winterbottom R (2001) Two new gobiid fish species in Trimma and Trimmatom (Teleostei: Gobiidae) from the Indian and Western Pacific Oceans. Aqua, J Ichthyol Aquat Biol 5:19-24

Winterbottom R, Burridge M (1992) Revision of Egglestonichthys and of Priolepis species possessing a transverse pattern of cheek papillae (Teleostei: Gobiidae). Can J Zool 70:1934-1946

Winterbottom R, Emery AR (1981) A new genus and two new species of gobiid fishes (Perciformes) from the Chagos Archipelago. Central Indian Ocean Environ Biol Fish 6:139-149
Winterbottom R, Erdmann MV, Caryani NKD (2015) New species of Trimma (Actinopterygii, Gobiidae) from Indonesia, with comments on head papillae nomenclature. Zootaxa 3973:201226

Winterbottom R, Hanner RH, Burridge M, Zur M (2014) A cornucopia of cryptic species - a DNA barcode analysis of the gobiid genus Trimma (Percomorpha, Gobiiformes). ZooKeys 381:79111

Winterbottom R, Southcott L (2008) Short lifespan and high mortality in the western Pacific coral reef goby Trimma nasa. Mar Ecol Prog Ser 366:203-208 